\title{
A PERCEPÇÃO EM EDMUND HUSSERL E EM MAURICE MERLEAU-PONTY
}

\author{
Maria Aparecida Viggiani Bicudo*
}

SÍNTESE - Neste artigo apresentamos nossa interpretação de obras de Edmund Husserl e de Maurice Merleau-Ponty lidas sob o enfoque da pergunta "qual o significado que esses autores atribuem à percepção?". Abordamos temas concernentes à constituição do sentido e da realidade mundana; ao desenvolvimento do simbólico; ao estabelecimento da intersubjetividade; à constituição da subjetividade e à unidade corps-propre. Trabalhamos o significado de verdade oferecida como presença e dada por perfis.

Palavras-chave: percepção; sentido; intersubjetividade; verdade.
ABSTRACT - This paper aims to make clear the meaning of perception as it. is elaborated in their works by Edmund Husserl and Merleau-Ponty. We study the constitution of meaning and of the worldly reality; the development of symbolics; the constitution of subjectivity and of intersubjectivity; the unity of "corps-propre". We show the meaning of truth understood as presence and given by perspectives.

Key-words: perception; meaning; truth; intersubjetivity.

\section{1 - Introduzindo}

Para os estudiosos da Fenomenologia, a percepção se constitui pedra angular para a compreensão da concepção de realidade e de conhecimento trabalhadas por essa escola filosófica. Sendo um conceito utilizado por diferentes abordagens teóricas tanto no campo da Psicologia, como no da Filosofia e no da Pedagogia, é importante que seja esclarecido, buscando-se explicitar os modos pelos quais a percepção se torna o primado na compreensão e interpretação do mundo.

$\mathrm{Na}$ trajetória percorrida para atingir um patamar de menor obscuridade e maior clareza, elegemos os estudos de Husserl e de Merleau-Ponty. Neles nos detivemos, procurando entender o significado que atribuem à percepção.

Neste artigo, apresentamos nossa leitura desses autores feita sob a perspectiva da pergunta "qual o significado que atribuem à percepção?", esperando contribuir com aqueles estudiosos interessados em trabalhar temas concernentes à constituição do sentido e da realidade mundana; ao desenvolvimento do simbóli-

- Universidade Estadual Paulista, UNESP, Rio Claro, SP.

\begin{tabular}{|l|l|l|l|l|l|}
\hline VERITAS & Porto Alegre & v. 42 & $\mathrm{n}^{2} 1$ & Março 1997 & p. 79-90 \\
\hline
\end{tabular}


co, ao estabelecimento da intersubjetividade e à constituição da subjetividade; à unidade corpo-encarnado.

\section{2 - A percepção na abordagem de Edmund Husserl}

\section{A atitude natural e a atitude fenomenológica}

Para a Fenomenologia, fenômeno, palavra derivada do verbo grego phaínestai, significa o que se manifesta, o que se mostra, o que aparece. E toda a complexidade do pensar fenomenológico, que se constitui em um método por ser um procedimento sistemático e rigoroso, decorre de sua busca de estudar o próprio fenômeno.

Fenômeno, o que se mostra. Mas, o que se mostra? A quem isto que aparece se mostra? De que modo isto aparece e como isto que aparece se expõe e se mantém no modo de expor-se?

Essas perguntas são respondidas diferentemente pelas teorias que assumem a postura da atitude natural e pela Fenomenologia que assume a atitude fenomenológica. Um dos pontos básicos que diferencia ambas as atitudes se refere ao modo pelo qual o objetivo é concebido. Nesse modo, a percepção tem papel preponderante, quando se trata da atitude fenomenológica.

De acordo com Husserl ${ }^{1}$, no mundo da atitude natural o objetivo diz respeito às coisas em si, ou seja, às coisas enquanto existentes fora do campo da percepção. Nessa atitude a postura imperante é a da ingenuidade, no sentido de aceitar o ponto de partida e as afirmações interconectadas de modo lógico, concernentes ao corpo de conhecimento de um campo do saber, sem crítica. Isto é, sem buscar justificar todas as afirmações a partir das suas raízes plantadas no ato gerador do conhecimento. Os estudos feitos são empiricamente conduzidos para abordar a realidade dos fenômenos naturais, sejam eles fatos, eventos, propriedades, conhecimentos, mente, significados. A própria mente e seus atos são considerados uma parte das coisas existentes e, como tais, estão aí para serem estudados empiricamente.

Moura $^{2}$ assim se expressa com referência às coisas do mundo natural: "são concebidas como conteúdos positivos pensáveis como distintos, por princípio dos fenômenos ou manifestações". Nessa atitude são tomadas como objeto tanto a coisa que se torna objeto para o sujeito, quanto a consciência que opera relações desse conhecimento. Isso significa que Eu e suas experiências subjetivas são assumidos como coisas em si, como parte do mundo. E o mundo é representado por imagens ou por signos, representação essa considerada tão mais correta quanto mais se adequar ao que representa.

Supor que a representação se faz por imagem ou por signo é supor um objeto exterior ao qual a consciência efetivamente não tem acesso, é supor uma trans-

1 Cf, HUSSERL, Edmund. Ideas relativas a una fenomenología pura y una filosofia fenomenológica. México. Fondo de Cultura Económica. 1949; p. 64 e seguintes.

3 MOURA, Carlos Alberto Ribeiro de. Crítica da razão na fenomenologia. São Paulo: Nova Stella, EDUSP. 1989. p. 164. 
cendência real do objeto frente à consciência, uma separação real entre o objeto e suas manifestações ${ }^{3}$.

A concepção de verdade com a qual a atitude natural trabalha está pautada nessa relação de adequação entre a representação e o representado. Verdade é entendida como adequação.

Na atitude fenomenológica, exposta de modo pleno em 1908 nas Meditações Cartesianas ${ }^{4}$ e a partir delas, a coisa não é tida como sendo em si, uma vez que:

$1^{2}$ não está além da sua manifestação e, portanto, ela é relativa à percepção e dependente da consciência;

$2^{\underline{ }}$ a consciência não é parte ou região de um campo mais amplo, mas é ela mesma um todo que é absoluto, não dependente, e que não tem nada fora de $\mathrm{si}^{5}$

A mudança da atitude natural para atitude fenomenológica é esclarecida por Husserl pela redução transcendental.

Para efetuar essa redução Husserl parte da objetividade do mundo natural, tal como assegurada pela filosofia cartesiana mediante a obtenção das idéias claras e distintas, propondo-se a compreendê-la. Portanto, ele não tem como tarefa autoimposta derrubar a crença da objetividade cartesiana, mas explicitar o que significam as afirmações sobre o mundo presentes no modo natural de explicá-lo.

É nessa busca que o significado por ele atribuída à Filosofia como Ciência Rigorosa ${ }^{6}$ se esclarece.

A fenomenologia não é uma ciência como a natural e humana que procede de modo ingênuo com respeito ao seu ponto de partida e à aceitação das suas afirmações justificadas no empiricamente comprovado. A ciência rigorosa examina todas as afirmações de modo a justificá-la plenamente mediante a redução transcendental.

Pela redução, os atos da consciência expõem-se, ou seja, toma-se ciência deles de modo que, pela reflexão, seu componente, são explicitadas as raízes cognitivas das próprias afirmações.

Nos parágrafos 41 e seguintes do The Crisis of European Science ${ }^{7}$, a redução transcendental é apresentada como sendo a ação de o Eu ficar acima do mundo que, agora pela apoché, adquire para esse Eu um sentido peculiar, o de fenômeno. Não se trata de negar o mundo, mas de tê-lo como um mundo-vida, enquanto um campo universal das experiências, previamente fixado. Esse é o mundo a priori das coisas espaço-temporais experienciadas na vida pré e extra-científica. Ele é o mundo-horizonte no qual sempre se está consciente dos objetos existentes e dos outros companheiros e onde se vive na certeza da sua existência. É esse mundo que é tomado como tema de investigação científica e, assim, o mundo objetivo a

Idem, p. 171.

4 HUSSERL, E. Cartesian Meditations an Introduction to Phenomenology. The Hague. Sixth Impression. Martinus Nÿhoff. 1977.

- MOURA, C. A. R., opus cit. p. 170.

- HUSSERL, E. Philosophy as Rigorous Science in Husserl, E. Phenomenology and the Crisis of Philosophy. New York:. Harper Torchbooks, 1965.

7 HUSSERL, E. The Crisis of European Sciences and Transcendental Phenomenology. Evanston: Northwestern University Press, 1970. 
priori se torna uma realização teórica mediada pela subjetividade e objetivada pela intersubjetividade.

A separação entre o real dado no mundo-vida e o objetivo real lógico é efetuada pela primeira epoché ou redução de primeiro nível.

Nessa epoché, coloca-se em suspensão o mundo-vida e efetua-se a reflexão por ser-se dele e nele consciente. Viver consciente do e no mundo-vida é estar-se atento a ele e a si próprio, experienciando e efetuando a certeza ôntica desse mesmo mundo.

É importante frisar que a redução transcendental ou epoché transcendental não é um ato temporário, acidental e isolado que se repete. Mas é uma atitude habitual decorrente daquele que modifica a sua postura no mundo-vida ao colocálo como tema de suas indagaçồes. Assim, o mundo-vida não é colocado em suspeita e nem o fluxo da existência interrompida para que a reduçăo possa ser realizada.

\section{Entendendo percepção no enfoque husserliano}

Como efetuar a epoché? Como sair da atitude natural e assumir a atitude fenomenológica?

De acordo com Husserl, é preciso considerar o mundo em sua concretitude e as experiências aí vivenciadas. No parágrafo 45 do The Crisis of European Science, fala do início da epoché como sendo o trabalho de expor-se o que é dado na intuição ou na percepção. Detém-se enfocando a percepção como um fenômeno complexo. Não a trata de modo abstrato, mas descreve a experiência de perceber-se uma coisa. Afirma que perceber uma coisa é vê-la, tocá-la, cheirá-la, ouvi-la; enfim, senti-la de diferentes maneiras e de acordo com as possibilidades dos sentidos. Em cada percepção, mostram-se aspectos diferentes do percebido. Assim, o percebido no ato de ver é diferente do percebido no ato de ouvir ou no ato de tocar, e assim por diante. Mesmo que se permaneça apenas no campo de um sentido, dão-se nuanças que surgem em múltiplas formas no fluxo contínuo da percepção.

"Uma coisa se dá, necessariamente, em modos de aparecer, em que o núcleo de algo realmente exibido rodeado por obra de apercepçōes, de um horizonte co-dado impropriamente e mais ou-menos vagamente indeterminado."

Essa afirmação poderia levar a uma interpretação prematura de que a coisa, na Fenomenologia, é transformada em atos subjetivos e a realidade objetiva, tal como entendida na perspectiva da atitude natural, é deixada a uma multiplicidade de vivências psicológicas.

É certo que para a Fenomenologia a coisa percebida é exibida de múltiplas maneiras. Porém isso não significa que ela se perca na multiplicidade das percepções. De acordo com Husserl, há sempre uma unidade que permeia as múltiplas maneiras em que a percepção da coisa se dá, formada por uma síntese de identificação ou uma síntese de transição do percebido no seu horizonte e no mundo-

8 HUSSERL, E. Ideas. op. cit. p. 99. 
horizonte ${ }^{9}$. Aí o que é percebido, e não o fruto de uma ilusão, aponta para uma multiplicidade de existentes perceptuais harmoniosamente relacionados. Isso leva à compreensão de que a coisa percebida tem uma unidade interna, oriunda da sintese de identificação, e uma externa, dada sua inserção no mundo-horizonte.

Ora, como ocorrem a unidade interna e a externa ná multiplicidade de percepções do objeto intencional ${ }^{10}$ que é sempre por perfis?

Na Crítica da Razão na Fenomenologia, Moura ${ }^{11}$, ao elucidar a redução, afirma que o vivido traz em si o seu objeto intencional, objeto dito, então, imanente. Porém isso não significa que o objeto seja uma parte do real vivido, caso em que se estaria lidando com a imanência real. Mas significa que as vivências subjetivas, que são psicológicas, têm um conjunto de conteúdos imanentes que são as sensações e as noesis, que dão origem ao fenômeno, no sentido noético. Esses fenômenos noéticos são processos psíquicos múltiplos e separados entre si por uma individualização, cuja responsável é a temporalidade imanente, isto é, a das vivências. Assim, cada percepção comporta fases em que, na passagem de uma a outra, nenhum momento poderá permanecer o mesmo e, concomitantemente, o objeto intencional surge como idêntico nas fases temporalmente separadas.

Esse jogo entre multiplicidade, característica da percepção, que é por perfis, e identidade do objeto intencional, determina a transcendência do objeto com relação aos aspectos psicológicos da consciência. Desse modo, o objeto intencional é o pólo de identidade imanente às experiências vividas; entretanto, é, também, transcendente a essas vivências por ser percebido como idêntico no fluxo temporal das experiências vividas.

\section{Intuição essencial}

Para Husserl, a atividade que reúne a multiplicidade, de modo que o idêntico seja percebido, é a intuição essencial. É nesse ato que a essência, ou eidos, é intuída, possibilitando a evidência da característica essencial do fenômeno. A essência designa um objeto intencional com novas características, uma vez que ele é dado na intuição essencial. Esses são os atos que geram a constituição dos objetos ideais ou das idealidades. Husserl afirma: "Uma intuição empírica ou individual pode se converter em intuição essencial (ideação) e a intuição essencial é também intuição e não mera representação". ${ }^{12}$

Falar de intuição essencial, de essência e de idealidade de objetos ideais pode levar à interpretação de que a fenomenologia husserliana permanece em nivel de abstração que inviabiliza o tratamento de e no mundo-vida e que se coloca em uma região atemporal. Entretanto, ainda ao efetuar a redução de primeiro nível ou do mundo-vida, Husserl é suficientemente claro para mostrar que esse não é o caso. Ou seja, expõe que a percepção é temporal, mundana e carnal.

\footnotetext{
Mundo-horizonte é entendido como campo perceptual.

${ }_{10}$ Todo objeto, na perspectiva fenomenológica, é intencional, uma vez que se trata da coisa enquanto dada na percepção.

" MOURA, C. A. R. Crítica da Razảo na Fenomenologia, op. cit. p. 157 e seguintes.

12 HUSSERL, E. Ideas. op. cit. p. 20.
} 


\section{A presentidade da percepção}

Husserl afirma que $o$ ato de perceber, ou seja, a percepção, ocorre no presente. Porém, sempre em um horizonte temporal, onde passado e futuro também estão presentes em um fluxo contínuo de retenções e de protensões. Desse modo, percepção e percebido se dão no mundo-horizonte, em perspectivas, quando 0 sentido vai se pondo e a significação se processando. É assim que os objetos intencionais passam a existir para a consciência com os significados a eles atribuídos mediante o modo pelo qual se fizeram presentes no mundo-horizonte. É assim que a realidade do mundo-vida passa pela subjetividade e que a certeza do mundo se estabelece.

Essa subjetividade, todavia, não é entendida como uma entidade abstrata. No parágrafo 47 do The Crisis of European Sciences, Husserl fala do movimento dos corpos vivos, tanto no caso do meu corpo vivo ${ }^{13}$ que se movimenta e que sente, portanto, percebe, como no movimento dos corpos-físicos, como ainda no dos outros humanos presentes no mundo-horizonte.

Ao considerar a presença do outro no mundo-horizonte, a fenomenologia husserliana transcende definitivamente a idealidade solipsista de um Eu puro que se auto-apreende e se autocompreende. Os outros, corpos vivos que se presentificam e percepções que são comunicadas, tecendo a rede da intersubjetividade, são tidos como co-sujeitos da experiência do mundo, formando o horizonte onde 0 encontro do Eu consigo mesmo e com o outro é possível.

Nesse mundo-horizonte, o que existe, em qualquer modalidade que seja, tem seus modos de dar-se à experiência, e o sujeito tem suas variações subjetivas de perceber-se e de realizar sínteses peŕceptivas comunicadas, de acordo com as peculiaridades, aos outros sujeitos.

\section{Verdade}

Ora, nessa abordagem, como entender a verdade?

De acordo com Husserl, nessa rede fluida do mundo-horizonte, tem-se apenas indicadores de realidades apontadas pelas subjetividades existentes. Cada sujeito, corpo vivo, indica um conjunto geral e possível de maneiras de experienciar um dado objeto. A totalidade dessas múltiplas maneiras é um horizonte de processos realizáveis e, como tal, concretizáveis em cada experiência, ou seja, na intenção operativa a ela inerente. Para cada sujeito essa intenção é o cogito. As maneiras de a coisa ser experienciada, que trazem consigo os modos pelos quais ela se doa e que se referem ao o quê e ao como dessa experiência, formam o cogitatum.

${ }^{13}$ Os temas percepção e corpo-vivo são investigados por Maurice Merleau-Ponty, que avança nas questões da intersubjetividade e da linguagem. A concepção de corpo-vivo desenvolve-se, sendo denominada corpo-próprio ou corpo-encarnado. 


\section{3 - A percepção na abordagem de Maurice Merleau-Ponty}

\section{Primazia ou primado da percepção}

Para Merleau-Ponty; o mundo percebido é a primeira realidade, o ser verdadeiro, o realmente real. Quer dizer com isso que o mundo percebido é o fundante sempre presente em toda racionalidade, em todos os valores e em toda existência. Para ele, essa tese não destrói nem a racionalidade, nem o absoluto. Porém, apenas tenta fazê-lo de volta à terra, ou seja, ao mundo do vivido.

Merleau-Ponty também não concorda com a análise que a Psicologia clássica faz da percepção. Diz que essa Psicologia reduz toda experiência ao que é julgado ser verdadeiro. Para ele a percepção não revela o ideal e o necessário, mas também não é uma ocorrência passageira livre, sem amarras, presas ao mundo presente. Ela ocorre no âmbito do todo. O sujeito que percebe, que toma um ponto de vista é o corpo encarnado, campo de percepção e de ação, que faz a síntese no horizonte da sua visada. Assim é impossível decompor a percepção em partes, fazendo-se dela uma coleção de sensações, pois o todo é anterior às partes, ele não é ideal e a sua significação não é conceitual. Para o autor considerado, se o todo fosse um conceito, a questão a ser posta seria: como eu pude reconhecê-lo nos dados sensíveis? E se fosse essa a pergunta teriamos que interpor intermediánios entre o conceito e o sensivel e, depois, intermediários entre intermediários...

A percepção encerra um paradoxo: 0 da transcendência $e$ da imanência do percebido. $O$ paradoxo já se inicia pela coisa percebida que existe apenas na medida em que alguém pode percebê-la.

Esse modo de ver a percepção afasta a clássica questão filosófica que se refere à existência do objeto em si. Porém, a percepção não esgota o percebido, uma vez que ela recorta perspectivas segundo um certo estilo do percebido. Portanto, admite Merleau-Ponty que há algo além do percebido: a coisa percebida aparece, assim, como imanente e transcendente à própria percepção.

Esse paradoxo leva a pensar sobre o aparecer de algo. Vê-se que o aparecer requer o ausentar-se; o visível requer o invisível.

Que conseqüências filosóficas podem ser tiradas do ponto de vista da Ontologia? E do ponto de vista do conhecimento?

A percepção oferece verdades como presenças. Isso significa que nossa relação com o mundo não é a de um pensador com o objeto do pensamento; não significa, também, que a unidade da coisa percebida, enquanto percebida por muitas consciências, seja a do tipo daquela dada na proposição; não significa, ainda, que a existência percebida seja comparável à existência real.

Presença é o estar-se no próprio momento em que as coisas, as verdades, os valores se constituem para nós. É o momento em que o sentido se faz. Ela se constitui como um logos nascente, pois é na experiência perceptiva que a unidade do mundo se constitui, que a existência é sentida como o viver o presente do corpo encarnado ${ }^{14}$.

${ }^{14}$ Entendido como campo perceptivo e prático. É o nosso ponto de vista no mundo, o lugar onde o espírito assume uma certa situação física e histórica. 
"A matéria é grávida de sua forma" ${ }^{15}$. Essa afirmação contém a idéia de que toda percepção ocorre em um certo horizonte, no mundo e na própria ação do corpo encarnado. A distinção classicamente feita entre matéria e forma não procede, tendo-se como ponto de referência a afirmativa acima. A matéria já é grávida de sua forma, pois é na ação, momento em que a percepção unifica, que a forma já se constitui junto com a matéria. Assim, desde o início, forma e matéria estão relacionadas. Trata-se, no dizer de Edmund Husserl, de uma "síntese de horizonte", a qual constitui a unidade dos objetos percebidos. Portanto, não é uma síntese intelectual que apreende o objeto como possível ou como necessário. Porém, é uma síntese em que o objeto é dado como uma série de percepções perspectivais, embora não seja dado exaustivamente em nenhuma delas. É por isso que na percepção, o objeto pode ser dado de modo deformado. Trata-se da deformação decorrente da perspectiva tomada do lugar ocupado pelo corpo encarnado. Este é o sujeito que toma pontos de vista, que completa a síntese entre o número infinito de visadas perspectivais do objeto que se recortam segundo um certo estilo, estilo este que define 0 objeto.

Um exemplo que Merleau-Ponty apresenta e que talvez esclareça o mencionado sobre unidade e sintese, que não são intelectuais, é o de uma lâmpada que se encontra em nossa frente ${ }^{16}$. Vemos um de seus lados, porém há outros lados não vistos. Para Merleau-Ponty esses lados estão lá escondidos, invisíveis. Para vêlos, é preciso mover a lâmpada ou o corpo encarnado movimentar-se em torno dela. Ele discorda, portanto, dos psicólogos que afirmam que o outro lado da lâmpada é representado, é tido como um possível. Diz não ser esse o caso, pois o representado e o possível são livres do em torno, ou seja, de todos os circunvizinhantes que constituem o aqui e o agora onde o meu corpo percebe a lâmpada.

\section{O mundo}

Na perspectiva de Merleau-Ponty não se fala do mundo como um objeto possível de ser tratado pela Matemática, pela Física e pelas demais Ciências Naturais. Não se pode falar do mundo de um ponto de vista externo ao nosso próprio corpo, antes de sua origem na experiência perceptual. Ao contrário, é por essa experiência que o mundo se constitui como tal para nós e é apenas por ela que as palavras racional e real têm sentido.

$\mathrm{E}$ aqui se coloca a questão de se, sendo assim, o "mundo" não permaneceria no campo privado de experiência de cada um, o que significaria que teríamos tantos mundos quantas pessoas, sendo que, então, não haveria a possibilidade de mundo, no sentido que Merleau-Ponty lhe atribui, ou seja, no de totalidade de coisas percebidas.

"Eu encontro na experiência do mundo percebido um novo tipo de relação entre corpo e mente. A evidência da coisa percebida jaz no seu aspecto concreto, na própria textura de

\footnotetext{
${ }^{16}$ MERLEAU-PONTY, M. O. primado da percepção e suas conseqüências filosóficas. Campinas: Papirus, 1990. p. 42.

16 Idem, p. 44.
} 
suas qualidades, e na equivalência entre todas as suas propriedades sensiveis - que levou Cézanne a dizer que se estaria apto a pintar odores." ${ }^{17}$

Essa passagem põe em evidência que o mundo só seria privado a cada pessoa se na experiência perceptiva do corpo encarnado não estivesse sempre, como contraponto, a coisa percebida, presente em sua concreteza.

A percepção ser o primado da experiência do mundo significa que há sempre um pólo da experiência centrado no corpo encarnado e outro centrado no que é percebido. A percepção é o encontro entre as forças de ambos. Assim, ela não se dá dentro do campo privado da experiência pessoal, mas está no campo de forças da ação e da intencionalidade do corpo e das coisas que estão no seu em torno. Merleau-Ponty exprime essa idéia com o seguinte exemplo:

\begin{abstract}
"Se eu e um amigo estamos diante de uma paisagem e se tento mostrar a meu amigo algo que eu vejo e que ele ainda não vê, não podemos dar conta da situação dizendo que eu vejo algo em meu mundo próprio e que tento por mensagens verbais suscitar no mundo de meu amigo uma percepção análoga; não há dois mundos numericamente distintos e uma mediação da linguagem que nos reuniria. Há, e sinto muito bem isso se me impaciento, uma espécie de exigência de que o que é visto por mim seja visto por ele. Mas, ao mesmo tempo, essa comunicação é pedida pela própria coisa que eu vejo, pelos reflexos de sol nela, por sua cor, por sua evidência sensivel.,"
\end{abstract}

Nessa passagem, dois aspectos do pensar do autor podem ser destacados, a coisa e a comunicação entre pessoas e a linguagem.

A coisa: é entendida como o percebido, o que se impõe "como real para todo sujeito que partilha minha situação"19. Assim, a coisa nẵo é algo que se impõe como verdadeiro para toda inteligência, nem é algo sentido na privacidade da sensação individual, mas é o que aí está "em seu aspecto concreto, na própria textura de suas qualidades....20.

A comunicação entre duas pessoas não se funda em uma sensória ou na aceitação de uma verdade intelectual, mas funda-se no fato de ambas estarem disponíveis às mesmas coisas e no fato de estarem em relação com o ser.

A percepção torna o ser acessível à pessoa, bem como torna a comunicação entre pessoas possível. Essa comunicação não faz a ponte entre dois mundos numericamente distintos mediados pela linguagem que faz surgir no outro percepções análogas ao do emitente. Porém, ela está enraizada na percepção do outro com quem partilha o mundo. O outro é para o sujeito-corpo encarnado - o outro eu mesmo, o alter-ego - uma vez que é, em princípio, aberto às mesmas experiências e às mesmas verdades que ele, sujeito, é. Do campo de sua subjetividade, o corpo encarnado vê outra subjetividade, percebe-a com iguais direitos e possibilidades, pois o comportamento do outro ocorre dentro do seu campo perceptual. Essa é a base da compreensão do comportamento do outro e do próprio compor-

17 MERLEAU-PONTY, M. "An Unpublished Text”. in: MERLEAU-PONTY, Maurice. The primacy of perception. New York: Northwestem University Press, 1964: p. 6.

18 MERLEAU-PONTY, M. O primado da percepção e suas conseqüências filosóficas. Campinas: Papirus, 1990. p. 50.

19

2o MERLEAU-PONTY, M. "An unpublished text". opus cit. p. 6. 
tamento. Essa é a base da intersubjetividade e, portanto, da objetividade do mundo percebido. "O mundo que é dado na percepção, de acordo com Merleau-Ponty, é o mundo que é concreto, o mundo-vida da experiência imediata constituído intersubjetivamente" ${ }^{21}$.

\section{Ligação entre consciência intelectual e consciência perceptual}

Considerando o primado da percepção cabe indagar quanto à sua validade universal. Essa pergunta faz sentido pois: a) como foi dito, o objeto pode ser dado à percepção de modo deformado; b) a descrição da experiência perceptual é de caráter psicológico, portanto privado; c) a experiência perceptual é ambígua ao deixar vazios passíveis de serem preenchidos por novas percepções do objeto, olhado sob outras perspectivas, pois há o aparecer e o esconder, o visível e o invisível.

Merleau-Ponty tem em conta que a descrição do mundo percebido leva a contradições. Pergunta-se se há algo como o pensamento logicamente coerente e sem contradições. Afirma que sua busca atém-se a essa interrogação. Persegue o pré-predicativo ou irrefletido, como assevera em muitos dos seus trabalhos, visando à compreensão do ponto primeiro da experiência do mundo, quando este passa a fazer sentido para o sujeito.

Aceitando a contradição da experiência perceptual do mundo, Merleau-Ponty atém-se a investigar essa experiência como 0 fundante de todo 0 conhecimento refletido, pelo qual e a partir do qual o racional e o lógico fazem sentido. Para ele, o irrefletido não é ao que voltamos ou o que antecede a reflexão, mas é o conquistado e o compreendido pela reflexão. A percepção não dá conta do entendimento de si mesma, nem do entendimento do mundo, não indo além dos seus próprios atos perceptivos. É a reflexão que viabiliza esse entendimento.

Porém, percepção e reflexão se dão no tempo, ou seja, desenrolam-se em instantes da vida que acontecem em um fluxo ininterrupto. Nesse fluxo, o pensar se faz modificando-se quanto ao sentido, em conformidade com as experiências vividas integradas em um conjunto de significações. A configuração desse conjunto se altera a cada instante, assim como também se modificam as experiências perceptivas. Com isso, o pensar reflexivo, na trilha do entendimento, está sempre se fazendo.

"Há pois de comum entre a percepção e o pensamento que ambos comportam um horizonte de futuro e um horizonte de passado e que ambos aparecem a si próprios como temporais embora não transcorram com a mesma rapidez nem ao mesmo tempo."

Essa é a base do entendimento de ciência para Merleau-Ponty que afirma "Esta concepção de saber é a única que não é mitológica, que é científica"23. O saber científico é compreendido como tendo seu primado na percepção do mundo,

21 Idem, p. 16.

MERLEAU-PONTY, M. O primado da percepção. Opus cit. p. 56.

$\infty$ Idem. 
quando este faz sentido para o ser perceptor que desenvolve seu pensar na rede de significações na qual está enredado, quando o cogito se impõe de modo ativo.

\section{Compreendendo o cogito}

Merleau-Ponty diz ${ }^{24}$ que há três modos de compreender o cogito.

Um primeiro modo é o dos psicólogos, que é o cogito de Descartes ao afirmar a primeira verdade do seu sistema filosófico "Penso, logo existo". É um cogito instantâneo, imediato, que se percebe ao pensar, dando-se, então, conta de sua existência, passando a ter certeza de que existe. Esse Eu que pensa e que assim se descobre é acessível apenas a si mesmo; define-se pelo pensamento ${ }^{25}$. A verdade primeira "Eu penso, logo existo" permanece a única, não há como sair de si.

Um segundo modo é compreender o cogito como apreensão dos fatos que o Eu pensa, como dos objetos a que o Eu penso visa, obtendo evidência tanto da existência privada do $E u$, como da existência das coisas pensadas pelo Eu. Nesse caso, cogito e cogitatum igualam-se. Não há lugar para a dúvida. O Eu pensante distingue, pelo pensamento, o mundo e as coisas. Separa de si seu corpo, pensado como uma coisa entre as coisas. Afasta-se do mundo, pondo-se como Eu isolado da realidade empírica.

O terceiro modo diz do cogito que se descobre em situação, ou seja, que se descobre ao mesmo tempo em que está engajado, enquanto pensamento particular, em certos objetos. Percebe-se em ato. Ao ter ciência de si em situação, sai da esfera do cogito psicológico, da subjetividade do "Eu penso", lançando-se à esfera da intersubjetividade. Descobre o mundo em si enquanto "o horizonte permanente de todas as suas cogitações" ${ }^{26}$ e como uma dimensão com relação à qual está continuamente se situando. Valoriza a percepção de si e a do outro (alter-ego). Mas, para tanto, é preciso que o "Eu seja também o seu exterior e que o corpo do outro seja ele mesmo"27.

Essa dialética do Eu e do Outro possibilitada pelo Eu ser seu exterior, ou seja, ser um corpo encarnado, não é inocente, podendo ser entendida idealmente como livre de obstáculos, mas é engajada no mundo. O cogito se efetua como percepção do $E u$ ante ele próprio, porém intermediado pela percepção que um espectador alheio, o outro, tem dele. O cogito-corpo encarnado, unidade que é indissolúvel, realiza-se em situação, apreendendo-se "não como um sujeito constituinte transparente por si [...] mas como um pensamento particular, um pensamento engajado em certos objetos, um pensamento em ato e é a esse título que estou certo de mim mesmo" ${ }^{28}$ (4, pág. 58). Sai, portanto, o cogito encarnado da esfera da verdade psicológica sem cair na da cogitante universal.

\footnotetext{
cf. MERLEAU-PONTY, Maurice. The primacy of perception. op. cit.

cf. MERLEAU-PONTY, Maurice. Fenomenologia de la percepción. Barcelona: Ediciones Península, 1975.

23 Idem.

23 MERLEAU-PONTY, M. O primado da percepção. Opus cit. p. 58.
}

n Idem. 


\section{Moralidade}

Compreendendo a vida como inerente ao mundo percebido e ao mundo humano, então a moralidade não pode se consistir na adesão privada a certos valores. Ela não se restringe ao Eu penso, entendido como psicológico, limitando-se à esfera do discernimento subjetivo. Também não se restringe à esfera do cogitante universal que regula o pensado pelo Eu psicológico. "Os princípios são mistificações se não ocorrem na prática; é preciso que eles animem nossas relações com 0 outro" ${ }^{29}$

A percepção do outro funda a moralidade, pois o corpo encarnado expõe-se de modo situado, fazendo com que suas ações, expectativas, perspectivas e valores participem do campo de visão de um outro Eu e de todos os outros, por recorrência. Esta participação entre os sujeitos é o campo da experiência moral. Esta, por ser experiência, é grávida de sua forma uma vez que o cogito a pensa, organizando os princípios morais animados, tornados vivos pela presença dos sujeitos, corpos-encarnados, um no campo perceptual do outro.

\section{4 - Finalizando}

Nesse autores fica claro que a percepção não é entendida como sensação ou como ocorrendo na esfera da subjetividade, em uma região separada do mundo e dos outros. Nem é tida como fonte de dados a respeito da realidade, considerados duvidosos, por serem passíveis de transformações conforme o estado de ânimo da pessoa que percebe ou segundo as vicissitudes ambientais.

Porém, a percepção é entendida como dando-se por perfis e oferecendo verdades como presença. Dar-se por perfis significa que 0 percebido pode ser visto sob diferentes enfoques, segundo o ponto do qual é olhado. Esse ponto é o pontozero, que é o do corpo-próprio ou corpo-encarnado. Portanto, a percepção é corpórea, é carnal e, como tal, contextuada. Nela, por seu intermédio, o mundo faz sentido para o sujeito. Nela, portanto, tem-se a gênese do logos, uma vez que desdobramentos do percebido, em interpretação e comunicação, permitem uma construção de uma rede de significados e de um mundo objetivo constituído na intersubjetividade.

MERLEAU-PONTY, M. The primacy of perception. Opus cit. p. 25 e 26. 